deafness and buzzing in the ears, deep-drawn noisy breathing, restlessness, and at last delirium, with wakefulness and a desire to get out of bed. All these symptoms, whith were not so severe as in the former case, censed quickly when the acid was withdrawn, and did not return, although there were two slight relapses of the rheumatic fever, which were treated with the perchloride of iron.

\section{ROYAL FREE HOSPITAL.}

CASE OF HYDROPHOBIA.

(Under the care of Dr. CockLE.)

For the following notes we are indebted to Mr. W. Carey Jeffries, resident medical officer.

Edward T-, aged thirty-two, porter on the Midland Railway, was admitted on Oct. $16 \mathrm{th}, 1876$, with symptoms of hydrophobia. He stated that in January last he had been bitten on the back of the left hand by a dog that had been found straying. The animal was locked in a room. During the night it had gnawed through the rope by which it was fastened, and is said to have killed and devoured a cat. The following morning when the patient entered the room for the purpose of feeding the dog, it flew at him, inflicting the wound alove mentioned; it then suddenly ran out of the house, and was not again seen. The animal was described as "looking wild," but not otherwise presenting any of the more ordinary signs of bydrophobia. For three days preceding the admission of the patient into the hospital, a marked peculiarity of manner was observed; he appeared depressed, complained of feeling ill, was hot at one time, at another cold, felt thirsty, but was afraid to drink, as he said it "took his breath away." When admitted into the hospital he complained principally of pain extending from the throat to the epigastric region; his aspect was anxious and excited, but he was quite sensible, and attempted to explain his feelings. He spoke of an indescribable sensation, and of an inability to swallow liquids, as they brought on severe suffocative attacks. When come water was given him to drink, the attack he spoke of was immediately induced; he gasped for breath, looked terrified, and if in the recumbent posture, raised himself quickly and leaned forwards. All these symptoms could be produced at any moment by pressing with the hand immediately below the ensiform cartilage.

The patient passed a restless night, and on the following morning was much worse; he became perfectly maniacal, the mania assuming a religious type. He was under the impression that he had secured a place in heaven, and had only twenty minutes longer to exist. The expression this belief produced on his countenance was most remarkable, the greatest ecstasy and terror being depicted thereon. He raved almost incessantly on this subject. When his attention could be arrested, and he was requested to take either medicine or nourishment, be would say "Anything but liquids." On two occasions be was induced to take the vessel containing some fluid in his hand; be would then, in the greatest agitation, only dip his finger in and hurriedly pass it between his lips. During the morning he had several of these suffocative paroxysms, some excited by currents of air from a window near his bed, which he begged to have closed, "as it made him choke;" others by a portion of the screen around his bed being drawn aside. When he recovered from the paroxysm, which was of brief duration, he cried out to have the "door closed" (meaning the screen), as he felt the cold wind blowing on him. During the afternoon he became less noisy, but had at intervals two or three violent and prolonged fits of struggling, during which respiration would at times cease, his face becoming purple, and the teeth clenched with such violence as on one occasion to break a tooth in pieces. A sudden profuse gecretion of saliva now took place, which he ejected in large quantities. During these later attacks he vomited frequently; the pupils were observed to dilate to their fullest extent, and to be quite insensible to the influence of light. Between these attacks he became quieter, the character of the delirium having changed; on several occasions he swallowed with but little apparent difficulty some milk and beeftea. Both urine and fæces were passsd in the bed. The temperature was normal : the pulse small and quickened.
Abont seven P.M. he was seized with an attack apparently of spusm of the glottis. When seen, respiration had entirely ceased; the face was cyanosed; the beart was beating regularly and with some degree of power. Artificial respiration and electricity were resorted to, the former being for a time attended with apparent good effect, the face becoming much less congested, but there was no ruturn of the natural respiration. Laryngotomy was also resorted to; all these means were, however, alike uvavailing, and in about half an hour from the last inspiratory effort the action of the heart was arrested.

The post-mortem examination showed congestion of most of the organs, but perfect absence of organic change. The lungs exhibited signs of the greatest amount of congestion, large quantities of almost black fluid blood pouring out wherever an incision was made. The brain and cord have been reserved for more minute examination. There was no appearance of inflammation or other change over the scar on the hand.

Dr. Cockle remarked that in this case the several stages - melancholic, maniacal, asphyxial - were well, even sharply, differentiated; sudden death from glottic spasm is certainly rarer than death from gradual exhaustion. It is needless to speak of treatment in a disease which at present is without remedy. Perhaps the most important point to note is the length of the period of latency-nine months. Here the case has value, as the dates were well authenticated.

\section{H I G H G A T E I N F I RMA R Y.}

A CASE OF IDIOPATHIC TETANUS.

(Under the care of Mr. Samuer Benton.)

Tномаs W-, aged thirty-one, a strong, muscular man, was admitted on the 31st of May, 1876.

He bad lately been at work in a brickfield, but for a fortnight he had been drinking hard and eating very little. Fcr ten days, while at work, he had stood in water, the sun being hot overhead. He bad not had any distinct rigor, but on May 28th be was rather relaxed in the bowels. On the 29 th he suffered pain and stiffuess in his head and back, and cramps in the calves, but he managed to do a full day's work in the brickfield. On the 30 th he worked three hours and a half, and then gave up.

He was admitted late in the evening of the 31st. The nurse reported that he passed a restless night, and in the morning he opened his mouth with difficulty, and swallowed badly. Decubitus, dorsal. He was unable to move without the greatest difficulty and pain. He perspired freely; could distend the cheeks, but could not whistle. Expression of face anxious. Muscles of abdomen rigid and tense. He complained of spasmodic pain in the back, epigastrium, groins, and calves. He had had two aperient pills, but his bowels were still confined. Palse 115, full and bounding, not easily compressible; temperature $98^{\circ} \mathrm{F}$.; respiration 24 .

June 2nd.- Had a bad night. Breath smells disagreeably. Touching his hands or any part of the body, or any noise in the ward, produces a short clonic spasm. He has a sharp spasm, causing opisthotonos, every three minutes, and lasting ten seconds. Ordered an enema of bouse medicine, castor oil, and gruel. To take thirty grains of bromide of potassium, and fifteen of chloral bydrate every four hours, and to have a warm blanket bath for one hour. Slop diet; three eggs, and four ounces of brandy.

3rd.-Bowels freely opened once; no alteration in the symptoms. Urine, forty ounces in twenty-four hours, sp.gr. 1030; contains urates; no albumen.

4th.- Slept for twenty minutes last night, then woke up and bit his tongue. Ordered a blanket bath for two hours and a half.

5 th.-Very little alteration; spasms not quite so frequent, but more severe. The blanket bath seems to have relaxed his masseters and the muscles of his abdomen a little. Ordered sixty grains of chloral hydrate and thirty drops of solution of morphia in two ounces of decoction of chinhcona, every night.

6th.-Slept for one hour, and woke up in a spasm. Is unable to protrude the tongue, which is flabby and thickly coated with white fur; swallows badly; is quite sensible, and answers questions rationally. 
7th.-He has had the same draught at night, with the addition of one drachm of liquid extract of ergot. To have in addition fifteen grains of chloral twice during the day.

8th.-Dozes a good deal. The spasms are more severe, but less frequent (about every hour). Pulse 105, rather weaker; tem perature $100^{\circ}$; respiration 33 , short.

9th.-Spits up with difficulty some muco-purulent sputa. The chest moves very little during respiration; breathing abdominal, and the diaphragm appears to be implicated. Body rigid; face cadaverous. Occasional muttering delirium.

10th.-A severe spasm during the night, in which he turned black in the face. Another spasm this afternoon, in which he died, thirteen days ufter the commencement of ilness. His temperature was rather low all through his illness, except on the last day; it never exceeded $101^{\circ} \mathrm{F}$.

Autopsy, forty-eight hours after death.-A powerfully-built, well-nourished framo. Chest, abdomen, and neck darkcoloured. Marked rigidity of body. Muscles flaccid; all of them of a dark-purple hue.-Chest: Right pleura slightly adherent from recent pleurisy. Pericardium unaffected; congestion of bases of both lungs.-Heart: Right auricle and ventricle full of black uncoagulated blood; a smaller quantity of the same kind of blood in left side of heart. No clots. Valves competent and healthy. The muscular tissue of the organ feels a little flabby.-Liver and kidneys healthy.-Brain: Nothing unusual in the naked-eye appearance. Very little if any subarachnoid hæmorrhage. Lateral ventricles full of blood-stained fluid. Fourth ventricle healthy. No alteration in medulla or pons.-Spinal cord: Normal consistence. The meninges are over-vascular, aud the veins congested, but not varicose. Upon section nothing abnormal is to be observed.

After the autopsy a caref ul microscopic examination of the brain and spinal cord was kindly made by Mr. W. H. Kesteven, who reported as follows:-The main disease appears to be in the brain. The cortical nerve-cells here are undergoing degeneration and atrophy. There is miliary degeneration of the white matter, immediately subjacent to the cortical grey matter of the convolutions. In the brain there is also considerable deposit on the walls of the vessels. In the cord there is nothing notable except a tendency to thickening of vascular walls.

\section{2ftedical Sucietres.}

\section{PATHOLOGICAL SOCIETY OF LONDON.}

THE ordinary meeting of this Society was held on the 7th inst., Mr. G. Pollock, the President, occupying the chair. A case of melanosis exhibited by Mr. S. Jones led to some valuable remarks by Dr. Hilton Fagge upon the significance of melanuria in this disease. Some interesting examples of disease of the skeleton were brought forward, including a case of anchylosis of the vertebræ and ribs, by Dr. Hilton Fagge; and a specimen of the spinal column, twenty-six years after fracture of the lumbar vertebræ, by Mr. Carr Jackson. Dr. Pye-Smith's case of suppuration of the brain and cord, following after cure of an empyema, raised the question of the pyæmic nature of cerebral abscess in general. A most instructive case in its clinical bearings was related by Dr. F. Taylor; it well illustrated the difficulty in diagnosing between lipomata and abscesses. The case was one of deep-seated lipoma in the neck, simulating enlarged thyroid, and post-pharyngeal abscess.

During the evening Mr. Benj. Mallam was elected a member of the Society.

Mr. SYDNEY JoNES presented to the meeting a young man twenty-three years of age, the subject of Multiple Melanotic Tumours, and gave the following history of the case. Three years ago the lad had a sore resulting from a graze of a black mole seated on the left leg, just below the inner tuberosity of the tibia; and six months later he came to St. Thomas's Hospital with a small rounded melanotic growth in the same situation. There was no enlargement of the femoral glands, and Mr. Jones having removed the growth, the patient left at the end of two weeks. He returned, however, in fifteen montha with a recurrence of the growth in the cicatrix, and numerous melanotic masses, varying in size from a pea to a small marble, in the left groin. He was again operated upon, and all the growths removed; and on a third occasion a further recurrence, both in the cicatrix and in the groin, again necessitated excision. Six ynonths later the melanosis became more diffused, for although there was now no further growth in the original seat, numerous small shot-like nodules had appeared in the skin of both thighs (most in the left), thorax, and neck; the nodules increasing rapidly in size, and forming black patches, which ulcerated. This was his present condition. There was no evidence of visceral complication, and no family history of tumours or cancer. $\mathrm{Mr}$. Jones regarded it as an example of melanotic sarcoma, taking its departure from an inflamed mole, and having a somewhat tunusual mode of dissemination-namely, by the lymphatic system. - Dr. HILTon FagGe inquired whether the urine had been examined with a view to the detection of melanotic pigment in it; and he exhibited two specimens of urine containing such pigment. The one was obtained, after death, from the bladder of a patient who succumbed to the effects of erysipelas following the removal of a melanotic tumour. Numerous melanotic nodules occurred in the lungs and mediastinum, but none in the liver or kidneys. The other was a specimen of pigment extracted from the urine of a case of melanotic sarcoma of the liver. The patient was admitted almost in a dying state, and all that could be made out during the few hours he lived was that he had a large, soft, and fluctuating tumour on the liver. The diagnosis of abscess then made might have been modified had the patient lived long enough to have allowed of the examination of the urine, and the detection in it of this peculiar pigment. The urine when drawn from the bladder after death had almost a natural appearance : it assumed a slightly greenish tint and became black on exposure. Virchow, in his work on Tumours, draws attention to this state of the urine in melanosis, and cites certain English writers-e. g., Mr. Norris, in 1820as being the first to have recorded it. (In his paper however, Mr. Norris only states that the urine was dark, like porter.) Virchow, however, apparently doubts the identity of the urinary pigment with the melanotic, and rather inclines to the belief that the former is due to indican, and its presence dependent upon coexistent disease of the liver. But the first case Dr. Fagge mentioned presented no affection of the liver, and, microscopically, the urine contained casts of the renal tubules of very black appearance, besides much pigmented renal and vesical epithelium. Dr. Fagge censidered the whole question to be shrouded in difficulty. Where was the original seat of formation of the pigment? Why was it that perfectly pigmented tumours were found side by side with others quite free from melanosis? Indeed the deposit of pigment seemed independent of the new growtb, for in his first case there were isolated patches of pigment in the stomach, bladder, and pelves of the kidneys. Nor was it restricted to sarcomata, for that same case was a true carcinoma.-Mr. JoNes said he had not met with melanuria in his case. He was willing to have the urine carefully analysed.-Dr. GREEN asked if the kidneys were involved in the cases related by Dr. Fagge, and the latter replied that in one case there were only some black spots beneath the mucous membrane of the pelvis.

Mr. SYDney Jones brought forward a living specimen of a remarkable Symmetrical Shortening of the Foot from Bone Disease. The patient, a man thirty-nine years of age, had within the last sizteen years suffered from disease of the right metatarsus, which had resulted in a shortening of that foot antero-posteriorly to the extent of three or four inches, and so symmetrically as to simulate congenital malformation. The shortening appeared to be due to the loss of the anterior parts of all the metatarsal bones and of the proximal phalanges, the tarsus and ankle-joint being quite perfect. The disease had not been contiuuously progressing during the whole period, but bad recurred at intervals of from four to seven years. The cage was unique in his (Mr. Jones's) experience.-Mr. A laban Doran, referring to an example of congenital shortening of the bones of both forearms, which he had brought forward last session, 